\title{
Hungry for tobacco: an analysis of the economic impact of tobacco consumption on the poor in Bangladesh
}

Debra Efroymson, Saifuddin Ahmed, Joy Townsend, Syed Mahbubul Alam, Amit Ranjan Dey, Ranjit Saha, Biplob Dhar, Aminul Islam Sujon, Kayum Uddin Ahmed, Oliur Rahman

\begin{abstract}
Objective-To investigate the extent of tobacco expenditures in Bangladesh and to compare those costs with potential investment in food and other essential items.

Design-Review of available statistics and calculations based thereon.

Results-Expenditure on tobacco, particularly cigarettes, represents a major burden for impoverished Bangladeshis. The poorest (household income of less than $\$ 24 /$ month) are twice as likely to smoke as the wealthiest (household income of more than $\$ 118 /$ month). Average male cigarette smokers spend more than twice as much on cigarettes as per capita expenditure on clothing, housing, health and education combined. The typical poor smoker could easily add over 500 calories to the diet of one or two children with his or her daily tobacco expenditure. An estimated 10.5 million people currently malnourished could have an adequate diet if money on tobacco were spent on food instead. The lives of 350 children could be saved each day.

Conclusion-Tobacco expenditures exacerbate the effects of poverty and cause significant deterioration in living standards among the poor. This aspect of tobacco use has been largely neglected by those working in poverty and tobacco control. Strong tobacco control measures could have immediate impact on the health of the poor by decreasing tobacco expenditures and thus significantly increasing the resources of the poor. Addressing the issue of tobacco and poverty together could make tobacco control a higher priority for poor countries.

(Tobacco Control 2001;10:212-217)
\end{abstract}

Keywords: poverty; malnutrion; tobacco expenditure; Bangladesh

UNICEF estimates that over 200 million children aged under 5 years in low income countries are malnourished, and that malnutrition contributes to about six million deaths among these children each year. ${ }^{1}$ Bangladesh, with a population of about 130 million people, is one of the poorest countries in the world. While life expectancy has increased over the past decade, in 1998 it was still only 60.5 for women and 60.7 for men. ${ }^{2}$ Nearly half the population of Bangladesh in 1995-96 lived below the poverty line, with about half of these living below the "hard core" poverty line. ${ }^{2}$ In 1998 , most households spent less than $\$ 82$ each month. ${ }^{3}$ In 1995, 30\% of families were classified as very poor, $22 \%$ as poor, and less than $1 \%$ as rich. ${ }^{4}$

Coexisting with this extreme poverty is a thriving tobacco industry. The use of chewing tobacco, bidis, and cigarettes is widespread. About 15 local companies compete for the lower end of the cigarette market. British American Tobacco (BAT), which owns the controlling share of Bangladesh's former tobacco monopoly, is a ubiquitous presence through its glossy media advertising, cigarette display cases, and storefront signs. In 1998, BAT Bangladesh reported pre-tax profits of approximately $\$ 15.9$ million, while it spent $\$ 3.4$ million on brand promotions and development. $^{5}$

Twenty years ago, it was suggested that "the nutrition-mediated effects of smoking, in terms of chronic undernutrition as well as survival, are likely to be far more important than the direct consequences of smoking on health" ${ }^{6}$ Although some statistics exist on tobacco use and household expenditures as part of national household expenditure data collection, we are unaware of any research specific to this area in Bangladesh. Tobacco has remained an issue of health and drug addiction, rather than being investigated in its relation to poverty.

\section{Methods}

Data on tobacco use and on household expenditures including tobacco was collected from the Bangladesh Bureau of Statistics (BBS). The following surveys on poverty, tobacco use, and sales figures for BAT Bangladesh, were also collected. Bangladesh has fairly complete data, much of it based on national surveys. Information in Analysis of basic needs dimension of poverty on household expenditures on basic goods and on tobacco are based on a stratified sample of households throughout Bangladesh, for a total of 32000 households. Age specific smoking rates and average expenditure for tobacco utilises data from the national Health and Demographic Survey. Statistics on smoking by income group, from Prevalence of smoking in Bangladesh, utilises information from 1299 respondents. The Household Expenditure Survey surveyed 3840 households 
Table 1 Male smoking rates by income group, $1995^{7}$

\begin{tabular}{ll}
\hline Monthly household income & $\%$ smokers \\
\hline$<\$ 24$ & 58.2 \\
$\$ 24-30$ & 56.7 \\
$\$ 30-35$ & 54.4 \\
$\$ 35-47$ & 53.7 \\
$\$ 47-59$ & 45.6 \\
$\$ 59-71$ & 46.1 \\
$\$ 71-94$ & 38.4 \\
$\$ 94-118$ & 36.3 \\
$\$ 118+$ & 32.3 \\
\hline
\end{tabular}

in 1991-92, and 7420 households in 1995-96. When repeated visits to the Bangladesh Bureau of Statistics failed to yield the primary sources, we used the summaries published in BBS's Statistical pocketbook, which are based on BBS surveys. Limitations include differing definitions of tobacco use (some surveys only inquire about smoking, which thus disregards all smokeless tobacco use); difficulty of respondents in calculating daily food consumption and tobacco expenditures; and the unavailability of some of the primary sources for data from BBS.

The data were analysed using Microsoft Excel to make comparisons of different expenditures and to calculate potential food purchases from tobacco expenditures. Calculations of potential food purchases from money spent on tobacco and their caloric value were made using food prices and calorie counts listed in BBS statistics for poor to medium grade foods. Advertised cigarette prices for 2000 were used where available. Where prices were not listed by the companies, the common market price of the cigarettes was used. Food prices were taken from a large market in Dhaka. (Food prices vary by type of food-for example, types of leafy green-and by the quality, as well as by the location. Some items are more expensive in rural areas, some less, but a comparable diet could be calculated with substitute foods for other parts of the country.)

All figures are adjusted for inflation to 1999/ 2000 values and, where originally in taka, converted to US dollars.

The calculations for year 2000 are based on the cigarette prices during that period. BAT has since decreased the price of Gold Leaf light from $\$ .90$ to $\$ .73$, and Benson \& Hedges from $\$ 1.43$ to $\$ .99$, but raised the price of Star from $\$ .38$ to $\$ .52$.

The exclusion of oral tobacco use from prevalence data for women represents a major

Table 2 Estimated number of poor smokers, $1996^{2}{ }^{7}$

\begin{tabular}{lclll}
\hline Age & $\begin{array}{l}\text { Male population } \\
\text { ('O00s) }\end{array}$ & $\begin{array}{l}\text { Number of poor } \\
\text { males ('O0Os) }\end{array}$ & $\begin{array}{l}\text { Smoking } \\
\text { prevalence }\end{array}$ & $\begin{array}{l}\text { Number of poor } \\
\text { male smokers ('000s) }\end{array}$ \\
\hline $15-19$ & 5979 & 2810 & 18.1 & 508 \\
$20-34$ & 14695 & 6907 & 57.3 & 3959 \\
$35-49$ & 9620 & 4521 & 72.4 & 3274 \\
$50+$ & 8028 & 3773 & 56.5 & 2131 \\
Total & 38322 & 18011 & & 9872 \\
\hline & Female population & Number of poor & Smoking & Number of poor \\
Age & ('000s) & females ('O00) & prevalence & female smokers ('000s) \\
\hline $15-19$ & 5826 & 2738 & 0.9 & 25 \\
$20-34$ & 14161 & 6656 & 3.3 & 220 \\
$35-49$ & 8853 & 4161 & 6.6 & 275 \\
$50+$ & 7079 & 3327 & 2.8 & 93 \\
Total 15+ & 35919 & 16882 & & 612 \\
\hline
\end{tabular}

flaw in the data. However, this exclusion was necessary as data were not available and this makes the results more conservative, as the estimation of poor women tobacco users is thus a gross underestimate.

\section{Results}

TOBACCO VERSUS BASIC NEEDS

The poor in Bangladesh spend most of their money on food and other essential goods, yet are still unable to provide even the basics for their families. But despite the high level of poverty in Bangladesh, smoking rates are relatively high. Men aged 35-49 years have the highest smoking prevalence at $70.3 \%^{2}$ and smoking prevalence is highest among the poorest. The highest rate, $58.2 \%$, is among men with a household income of less than \$24/month (table 1). Smoking prevalence declines proportionally as income increases, with the lowest rate, $32.3 \%$, being for men with a monthly household income of $\$ 118 /$ month $^{2}$ or more. ${ }^{7}$

While smoking rates by women are much lower than for men, rates of oral tobacco use by women, for which no reliable figures are available, are thought to be quite high. Where women do smoke, they tend to smoke tobacco in forms that are cheaper than cigarettes, such as bidis, which women are six times more likely to smoke as compared to cigarettes.

Calculations of the number of poor smokers in Bangladesh are shown in table 2. Statistics from the Household Expenditure Survey show poverty, in terms of the population unable to consume 2122 calories/day, as being over $47 \%$ for the three periods measured between 1988 and $1996 .^{\circ}$

The cutoff point we utilised for poverty in table 2 is based on the Bangladesh Bureau of Statistics criteria $^{34}$ is a monthly household income of less than $\$ 70$ - the category into which $40 \%$ of Bangladeshi households, and presumably most poor families and malnourished children, fall. The figures yield a total of 9.87 million poor male smokers and 612000 poor female smokers aged 15 years and over, for a total of over 10.48 million poor smokers. (While figures for smoking by poverty rate are available for men, the calculation for women involves the smoking rate across income groups, by age.)

Cigarettes are the most expensive form of tobacco consumed, followed by bidis, with hukka, pipes, and other forms the cheapest. In 1997, average tobacco expenditure for those who use it ranged from a low of $\$ 1.29$ a month for women who smoke hukkas, to a high of $\$ 7.24$ a month for men who smoke cigarettes. ${ }^{2}$ By comparison, per capita expenditure on clothing, housing, health, and education totals only $\$ 2.92$ per month, or $40 \%$ of the average male monthly expenditure on cigarettes. ${ }^{9}$ Cigarettes are by far the most widely advertised tobacco product.

The typical male cigarette smoker spends over five times as much on cigarettes as the per capita expenditure on house rent, 18 times as much as for health, and 20 times as much as for education (fig 1). For women, the figures are only slightly less striking; women who smoke 


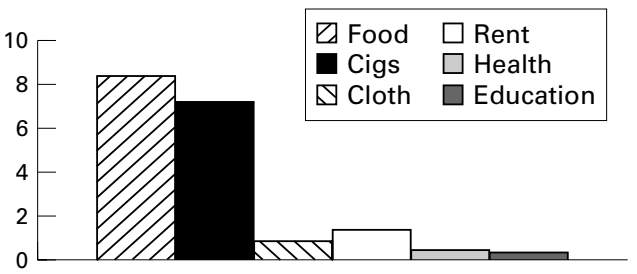

Figure 1 Men's monthly cigarette expenditures versus per capita monthly expenditure for basic needs, 1997. Cloth, clothing.

hukkas spend almost as much on tobacco as the per capita expenditure for housing, and over three times as much as the per capita expenditures for health and education. As there is no government support for the poor for clothing or housing, and virtually none for education or health care (per capita government spending on health in 1999 was $\$ 3.56^{10}$ ) these numbers represent actual total expenditures on these items. Women's expenditure on average for cigarettes is more than half the per capita expenditure on food. Men spend more than $86 \%$ as much on their cigarettes as the average per capita expenditure on food. Spending per household on tobacco represents $1.3 \%$ of total household expenditure for rural areas, 3.3\% for urban areas, or $1.4 \%$ for the country as a whole. ${ }^{9}$

As shown in table 3, the poorest households spend half as much on tobacco as on health, and almost 10 times as much on tobacco as on education. While the lowest income groups spend the lowest percentage of their income on tobacco, the numbers do not increase steadily; for instance, both those with household expenditure between \$35-\$47 and \$213-\$236 spend $2.6 \%$ of their income on tobacco, with the average for all groups being 2.8\% (not shown). The poorest spend much more on tobacco than on education; this levels out for middle income groups, with the upper half of income groups spending a smaller percentage of their income on tobacco than on education. For most groups, a similar amount is spent on tobacco as on health.

In fig 2 we reallocated average male smokers' monthly cigarette expenditure of $\$ 7.24$ to basic needs, using the proportions given as national

Table 3 Expenditures on tobacco versus health and education, 1995/6 ${ }^{8}$

\begin{tabular}{lclll}
\hline & $\begin{array}{l}\text { Percentage of total } \\
\text { households in that } \\
\text { expenditure group }\end{array}$ & $\begin{array}{l}\text { Percentage of total } \\
\text { income spent on } \\
\text { tobacco }\end{array}$ & $\begin{array}{l}\text { Ratio of } \\
\text { expenditures on } \\
\text { tobaccolhealth }\end{array}$ & $\begin{array}{l}\text { Ratio of } \\
\text { expenditures on } \\
\text { tobaccol } \\
\text { education }\end{array}$ \\
\hline$<\$ 18$ & 2 & 1.5 & 0.5 & 9.7 \\
$\$ 18-24$ & 2 & 1.7 & 0.7 & 8.4 \\
$\$ 24-30$ & 4 & 2.3 & 1.0 & 6.9 \\
$\$ 30-35$ & 5 & 2.5 & 1.1 & 4.9 \\
$\$ 35-47$ & 12 & 2.6 & 1.2 & 4.2 \\
$\$ 47-59$ & 13 & 2.5 & 1.0 & 3.2 \\
$\$ 59-71$ & 12 & 2.4 & 1.0 & 1.7 \\
$\$ 71-94$ & 17 & 2.1 & 0.9 & 1.2 \\
$\$ 94-118$ & 11 & 2.6 & 1.0 & 0.9 \\
$\$ 118-142$ & 7 & 2.9 & 1.2 & 0.8 \\
$\$ 142-165$ & 4 & 2.8 & 1.3 & 0.6 \\
$\$ 165-189$ & 3 & 3.0 & 1.1 & 0.7 \\
$\$ 189-213$ & 2 & 3.6 & 1.2 & 0.4 \\
$\$ 213-236$ & 1 & 2.6 & 0.8 & 0.7 \\
$\$ 236-295$ & 2 & 3.7 & 2.1 & 0.8 \\
$\$ 295-354$ & 1 & 3.7 & 2.1 & 0.7 \\
$\$ 354-413$ & 1 & 4.5 & 1.7 & 0.7 \\
$\$ 413-472$ & 1 & 3.5 & 1.5 & \\
$\$ 472+$ & 2 & 4.4 & & \\
\hline
\end{tabular}

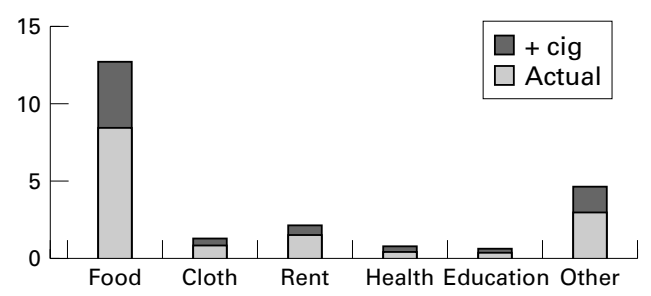

Figure 2 Per capita monthly expenditure: actual and with men's monthly cigarette expenditures allocated across categories (national average), 1997. Cloth, clothing.

averages $(58.8 \%$ for food, $5.6 \%$ for clothing, $9.5 \%$ for housing, $2.8 \%$ for health, $2.5 \%$ for education, and $20.8 \%$ for other). ${ }^{9}$ This represents the way a typical non-tobacco using person might be expected to spend the money that would otherwise go to tobacco use. (The additional money was added to the average expenditures rather than shifting it from "other", since the average smoker spends more on cigarettes than the average household for the category "other".)

Across income groups, people would be likely to spend an additional $\$ 1.70-\$ 4.40$ per month for food, with similar but smaller increases across other categories. For cigarette smokers, this would mean an average increase of over $50 \%$ in their monthly food expenditure. Rural cigarette smokers would have over $50 \%$ more money available for health care, and an urban cigarette smoker an additional $34 \%$ for education. ${ }^{9}$

\section{TOBACCO VERSUS FOOD}

As spending on food increases, malnutrition (underweight for age and stunting) decreases. ${ }^{11}$ The poorest households spend the highest proportion of their income on food, but are also the most likely to have malnourished children in their household. Thus, they would benefit the most by shifting their tobacco expenditures to food. Most Bangladeshis live in the countryside, but the rural poor are mostly landless or virtually landless. Use of cigarettes and bidis in rural areas is highest for those who own less than half an acre of land, ${ }^{8}$ so growing extra food to compensate for tobacco expenditures is not an option.

Those with a monthly expenditure of less than $\$ 45$ a month spend $73 \%$ of that money on food, whereas the figure for those with a monthly expenditure of $\$ 45-\$ 111$ is $66 \%$. $^{9}$ This averages out to over $69 \%$ of household monthly expenditure going to food. Nearly $78 \%$ of calories in the Bangladesh diet are supplied by cereals. ${ }^{3}$ We can therefore assume that the poor would spend most of their increased food budget on rice, while smaller numbers of calories of less commonly consumed foods could have a huge impact on children's diet.

Table 4 shows average daily expenditures for tobacco in 1997 for men and women who use it, by type of tobacco product, and the number of calories from rice that each sum could purchase, using the 1997 price of $\$ 0.08$ for 1000 calories of rice. The average male tobacco user could purchase 1402 calories of rice per day with his tobacco money; the figure for women is 770 calories. The minimum daily calorie 
Table 4 Average daily expenditure on tobacco, $1997^{2}$

\begin{tabular}{llllll}
\hline \multirow{2}{*}{ Type of tobacco } & \multicolumn{2}{c}{ Average expenditure on tobacco } & & \multicolumn{2}{c}{ Equivalent in calories of rice } \\
\cline { 2 - 3 } & Male & Female & & Male & Female \\
\hline Average for all types of tobacco & $\$ 0.11$ & $\$ 0.06$ & & 1402 & 770 \\
Bidi & $\$ 0.06$ & $\$ 0.07$ & & 797 & 907 \\
Cigarettes & $\$ 0.24$ & $\$ 0.15$ & & 2942 & 1869 \\
Hukka/pipe, etc & $\$ 0.06$ & $\$ 0.04$ & & 715 & 522 \\
\hline
\end{tabular}

requirement varies by age and sex, from 1094 for children aged 3 years and under, to a peak of 2782 for males and 2544 for females aged 18-29 years. $^{3}$

Even cheap cigarettes are expensive when compared to foods. In year 2000 prices, a 20-pack of Navy (one of the most heavily advertised but mid cost brands) costs almost as much as a litre of milk; less than two packs would pay for a litre of soybean oil. A pack a day of Navy would consume $16 \%$ of the average income for a Bangladeshi. ${ }^{3}$ An egg costs little more than a stick of Gold leaf light. A pack of Gold Leaf light could pay for 3.4 dozen small bananas, $6.7 \mathrm{~kg}$ of spinach, 1.3 litres of soybean oil, or $3.4 \mathrm{~kg}$ of rice. With $\$ 0.73$ - a few hours' wage for a rickshaw puller-one could buy either $0.5 \mathrm{~kg}$ of beef, or $5.5 \mathrm{~kg}$ spinach, or over $1 \mathrm{~kg}$ of lentils, or a dozen eggs, or one pack of John Player Gold Leaf regular cigarettes. A smoker of a pack a day of Star or Scissors spends $\$ 0.38$ each day, or over $\$ 11.50$ each month. If he spent $70 \%$ of that money on food instead, he could easily add 800 calories each day to his family's diet, in the form of lentils, potatoes, fish, beef, and spinach.

BAT Bangladesh's gross turnover in cigarettes in 1998 was over $\$ 293$ million. ${ }^{5}$ That figure could have purchased over 4.7 billion eggs, enough to feed almost 13 million children an egg a day. Meanwhile, egg consumption in 1996 (latest year in which statistics are available) averaged one egg per person per month. ${ }^{2}$

Per capita monthly expenditure for tobacco is higher in both rural and urban areas than that for milk, and higher in urban areas than for leafy green vegetables. People spend nearly as much in cities for tobacco as for lentils (the main protein source in the Bangladeshi diet). Nationally, for each of the high nutrient foods shown in fig 3, tobacco expenditures represent more than half the expenditures for food. ${ }^{9}$

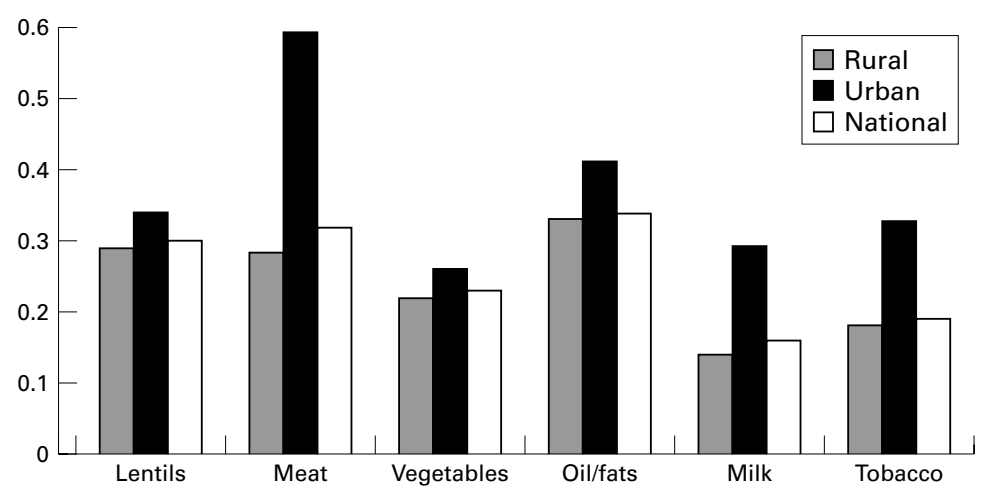

Figure 3 Monthly per capita expenditure on tobacco versus food items, 1997.
TRENDS IN CONSUMPTION OF TOBACCO VERSUS FOOD

Poverty, as measured by daily caloric intake, increased in urban areas from 1991 to 1996 (the most recent years for which statistics are available) from $46.7 \%$ (6.82 million people) to $49.67 \%$ (9.56 million), though it improved slightly in rural areas from $47.64 \%$ (44.81 million) to $47.11 \%$ (45.73 million); for the country as a whole, poverty worsened from $47.52 \%$ (51.63 million) to $47.53 \%$ (55.28 million). ${ }^{8}$ Given the high rates of tobacco use among the poor, it is plausible that development gains over the past several years have been significantly offset by diversion of income to tobacco.

Comparing the 1997 figures for those for 1995 shows that the general trend is towards increasing expenditures for tobacco. Daily expenditures for tobacco rose from $\$ 0.07$ to $\$ 0.11$ for men, and from $\$ 0.04$ to $\$ 0.06$ for women. Meanwhile, the price of rice fell, so that the opportunity cost-the amount of rice that could have been purchased with tobacco money-further increased. While the average male smoker could have purchased an additional 1837 calories of rice with his cigarette money in 1995, the figure rose to 2942 calories in 1997. For women smoking bidis, the figure tripled, from 302 calories in 1995 to 907 in 1997. The potential in calories of rice for the average tobacco user nearly doubled for both men and women, from 721 and 419 respectively in 1995 , to 1402 and 770 calories in $1997 .^{2}$

From 1992 to 1996, per capita cigarette consumption increased by $33 \%$. A similar increase occurred in the consumption of cabbage (though only from 0.6 to $0.8 \mathrm{~kg}$ / person/year) and to a lesser degree of milk and fish, while per capita consumption of many other items increased only slightly, or even declined. Rice, the staple of the Bangladeshi diet, increased by only $1 \%$ over the period, while banana consumption dropped by $6 \%$ and eggs by $29 \%{ }^{2}$

If cigarette consumption per capita in 1994-95 had remained the same as in 1992-93, and the money that was spent on cigarettes in that year had gone to food, Dhaka residents could have consumed almost $15 \%$ more meat, $14 \%$ more milk or $79 \%$ more eggs.

\section{Discussion}

If national economic improvements lead to greater expenditure on tobacco but not on food, then the benefit of the economic growth will be erased. Increased spending power is not sufficient to guarantee improvements in well being, particularly where tobacco companies advertise their products freely to an uneducated public. In Bangladesh, where tobacco prices remained low and advertising proliferated, the most significant spending change over the years was in more money going to cigarettes, rather than food. In that situation, reducing taxes on tobacco products may be regressive, as it provides an incentive for more poor people to use tobacco and to spend more of their income on tobacco. ${ }^{12}{ }^{13}$ As others have 
also observed, since the poor are more responsive to price and thus more likely to reduce usage or quit when prices increase, they may actually save money when taxes increase. ${ }^{14-16}$

UNICEF estimates that Bangladesh loses the equivalent of more than $5 \%$ of its gross national product in lost lives, disability, and productivity caused by malnutrition. ${ }^{17}$ Malnutrition is blamed for the deaths of over 700 children under age 5 each day in Bangladesh. ${ }^{18}$ In $1995-96,60 \%$ of Bangladeshi children aged between 6 months and 6 years were malnourished (deficient height-for-age, weight-for-height, or both). ${ }^{11}$ For those who survive, lifelong impairment can result, including poor physical and mental ability, more illness, and little ability to be economically productive.

Half of the poor consume between 1805 and 2122 calories per day. ${ }^{8}$ For this group, 400 additional calories or less per day would bring them into sufficiency. For those consuming less than 1805 calories, more than 400 additional calories are needed. In either case, the average tobacco user could provide sufficient calories to cross the poverty line as measured by caloric intake. This means that each tobacco user represents one or more people-whether the smoker or his wife or child-who is needlessly going hungry.

If the poor stopped using tobacco and re-allocated just $69 \%$-the percentage of income going to food in the lowest income groups - of their tobacco expenditures to food, then over 10.5 million fewer people would be malnourished, about half of whom had been below the "hard core" poverty line of less than 1805 calories/day. In addition, half of the children currently dying daily from malnutrition350 children-could be saved if their parents redirected their tobacco money to food. This translates to 127750 fewer deaths of children under age 5 per year.

While it is true that not all savings from tobacco would be reallocated to basic needs if a poor person stops using tobacco, it is also certain that the money spent on tobacco will not be spent on food. Given the high rates of tobacco use among the poor, even if a fairly small percentage reallocated their spending to food, the benefits in terms of improved nutrition and children's health would be considerable.

Some economists, particularly in the USA, ${ }^{14}$ would argue that people should be allowed to make free choices about their personal expenditures, no matter how it affects them and their families. However, there are various flaws to that argument. First, increasing tobacco taxes does not represent coercion; there is no clear conflict between raising taxes and respecting people's free choice. Second, a conflict with free choice comes with the addictive nature of tobacco: once a person becomes addicted, he or she can no longer be said to choose freely whether or not to spend money on tobacco. Tobacco advertising, while not coercion, influences purchasing decisions, particularly in the absence of information about the harm of tobacco; the combination of a

\section{What this paper adds}

The economic aspects of tobacco frequently focus on price elasticity, tax revenues, and spending on tobacco related disease. The opportunity cost of tobacco use for the poor has received much less attention. This paper addresses tobacco expenditures in Bangladesh, focusing on the potential increase in food consumption if tobacco use declined. Tobacco expenditures are significant when compared to expenditures for basic needs and suggest a neglected issue both in tobacco control and in poverty alleviation.

comprehensive ban on tobacco promotion, some mass education, and increased taxes would encourage the poor to spend their money more wisely. Third, freedom of choice does not supersede other human rights; governments have the right, and one may even suggest the obligation, to encourage the poor to utilise their scarce resources for basic goods for themselves and their family, rather than on items like tobacco and alcohol. More emphasis needs to be paid to the need to increase tobacco taxes while safeguarding the situation of the poor. ${ }^{13}$

\section{CONCLUSION}

The tobacco companies argue that increasing tobacco taxes is regressive. This is not necessarily so, as economists have shown. ${ }^{12}{ }^{13} \mathrm{It}$ is no service to the poor to encourage them to become addicted to tobacco products, by allowing advertising and maintaining a low price. Despite - or in fact because of - tobacco prices remaining fairly stable in Bangladesh, per capita expenditure on tobacco has increased significantly. The tobacco companies argue for the right to smoke, but such a right needs to be balanced against the right of smokers' wives and children to eat. Industry officials argue that tobacco consumption is not a problem in Africa because life expectancy is low in many countries. ${ }^{19}{ }^{20}$ Part of the reason for this is poverty. Long before serious tobacco related illness sets in, tobacco wreaks its damage via the pocketbook. If the price of tobacco were raised, the poor would be likely to consume less tobacco and spend less on tobacco. Banning tobacco promotion could further enhance this effect. The poorest tobacco users who continue to smoke could switch from cigarettes to bidis or other cheaper tobacco products, so the taxes would not further harm their already precarious financial situation. While the government of Bangladesh is not currently considering raising the tobacco tax, it is considering tobacco control legislation. Governments should be made aware of the beneficial fiscal aspects of tobacco tax increases, and of strategies for ensuring, in situations where cheaper tobacco is not available, that such increases will not harm the poor.

From our research, we conclude that tobacco use is a neglected issue in poverty reduction-and that poverty is a neglected issue in tobacco control. A further benefit of 
tobacco control measures could be decreased expenditure on non-essential goods, and a concurrent improvement in the health and well being of the poor. Major improvements in quality of life and nutritional status could occur if governments focused attention on tobacco control measures, and if the tobacco control movement utilised the poverty argument to convince governments of poor countries, and other agencies, to join the tobacco control movement.

1 Annan K in UNICEF. The state of the world's children 1998. Oxford and New York: Oxford University Press for UNICEF, 1998.

2 Bangladesh Bureau of Statistics. Statistical pocketbook Bangladesh 1998. Dhaka:BBS, 1999.

3 Bangladesh Bureau of Statistics. Analysis of basic needs dimension of poverty volume III. Dhaka: 1998.

4 Bangladesh Bureau of Statistics. Analysis of basic needs dimension of poverty volume I. Dhaka: 1995.

5 British American Tobacco Bangladesh, Reports \& Account 1998.

6 Cohen N. Smoking, health, and survival: prospects in Bangladesh. Lancet 1981;i:1090-3.

7 Bangladesh Bureau of Statistics. Prevalence of smoking in Bangladesh. Dhaka: BBS, 1996.
8 Bangladesh Bureau of Statistics. Household expenditure survey 1995-96. Dhaka: BBS, 1998.

9 Bangladesh Bureau of Statistics. Analysis of basic needs dimension of poverty volume II. Dhaka:BBS, 1997.

10 Government of Bangladesh. National health policy, Dhaka: Ministry of Health and Family Welfare. 2000 (in Bengali).

11 Bangladesh Bureau of Statistics Child nutrition survey of Bangladesh 1995-96. Dhaka: BBS, 1997.

12 Townsend J. Cigarette tax, economic welfare, and social class patterns of smoking. Applied Economics 1987;19:35565.

13 Townsend J, Roderick P, Cooper J. Cigarette smoking by socioeconomic group, sex, and age: effects of price, income, and health publicity. BMF 1994;309:923-7.

14 Warner KE, Chaloupka FJ, Cook PJ, et al. 1995. Criteria for determining an optimal cigarette tax: the economist's perspective. Tobacco Control 1995;4:380-6.

15 Bobak M, et al, and Musgrove P, et al. Chapters in: Jha P, Chaloupka FJ, eds. Tobacco control in developing countries. Oxford, 2000

16 Jha P, Chaloupka FJ. Curbing the epidemic. Washington DC: World Bank, 1999.

17 UNICEF. The state of the world's children 1998. Oxford and New York: Oxford University Press for UNICEF, 1998.

18 Anon. Over 700 children dying everyday, claims NFB study. The Bangladesh Observer, 29 April 2000.

19 Masebu P. Africa remains a viable market for cigarette companies. PANA, 31 May 2000

20 Saloojee, Y. Coughing up profits in Africa. INGCAT Update, 2nd quarter, 2000. 